\title{
CORINTO GRECORROMANA: CENTRALIDAD Y PERIFERIA EN LA ANTOLOGĹA PALATINAY OTRAS FUENTES ESCRITAS ANTIGUAS
}

\author{
Greco-Roman Corinth: Core-periphery in the Greek Anthology and other ancient \\ written sources
}

\author{
Elbia HaydeÉ Difabio* \\ Universidad Nacional de Cuyo \\ elbiad@ffyl.uncu.edu.ar
}

\section{Palabras clave \\ Corinto; \\ Antología Palatina; otras fuentes escritas; lazos jerárquicos}

\begin{abstract}
Resumen
En la Antología Palatina, representantes de distintas escuelas literarias, algunos más célebres que otros, junto con autores anónimos, recuerdan las ciudades antiguas -en Grecia y luego en Roma, además de las zonas de influencia de ambas-, como cuna de inolvidables referentes históricos o míticos, foco de contiendas bélicas o de victorias en competencias y juegos, epicentros de curación o modelos de paisaje natural o urbano, entre otros motivos de inspiración. En el marco del proyecto SIIP 2019-2021, "La política como eje vertebrador en la Grecia Antigua. Expresiones discursivas en fuentes diversas", se examina una de ellas, Corinto y su ciudadela Acrocorinto, presentes en alusiones de unos versos o en poemas completos de la compilación. Previa traducción directa personal de la fuente original y de la confrontación de diversas traducciones (latina -que se transcribe-, española, inglesa e italiana), se sistematizan los rasgos que el imaginario colectivo retuvo, en consonancia con las posibles causas movilizadoras que inspiraron a sus creadores. Se han consignado las notas filológicas consideradas más oportunas. La consulta de Homero, Hesíodo, Heródoto, Píndaro, Pausanias, Estrabón, Higino, Cicerón, Alcifrón, Elio Arístides y Diógenes Laercio corrobora, complementa y amplía el contenido de los epigramas, para la mejor comprensión de la ró $\lambda$ is en la geografía, la historia, la filosofía, el arte, el deporte, la religión, el mito y las costumbres, verificando también los lazos jerárquicos con el resto de Grecia y con Roma.
\end{abstract}

\section{Keywords}

Corinth;

Greek Anthology;

other ancient written;

hierarchical ties

\begin{abstract}
In the Greek Anthology, poets of different literary schools -some more famous than others-, as well as anonymous authors, remember the ancient cities -in Greece and then in Rome, besides the areas of influence of both-, in the Greek Anthology. These places are evoked as the home of unforgettable historical or mythical references, as the focus of warfare or victories in competitions and games, epicenters of cure or models of natural or urban landscapes, among other reasons. This study is part of SIIP 2019-2021 project, "Politics as the backbone in Ancient Greece. Discursive expressions in diverse sources". Both Corinth and its citadel Acrocorinth are present in some lines or in complete poems of the compilation. Previous the direct personal translation of the Greek original and the comparison with other different translations (Latin -which is transcribed-, Spanish, English and Italian languages), the features that the collective imagination retained are systematized, in line with the possible mobilising causes that inspired their creators. The most appropriated philological notes have been included. The query of Homer, Hesiod, Herodotus, Pindar, Pausanias, Strabo, Hyginus, Cicero, Alciphron, Aelius Aristides and Diogenes Laertius confirms, complements and extends the epigrammatic content, for a better understanding of the $\pi$ ó $\lambda 1 \zeta$ concerning its geography, history, philosophy, art, sports, religion, myth and customs, also verifying the hierarchical bonds with the rest of Greece and Rome.
\end{abstract}




\section{Corinto grecorromana: centralidad y periferia en la Antología Palatina y otras fuentes escritas antiguas}

En el marco del proyecto SIIP 2019-2021, "La política como eje vertebrador en la Grecia Antigua. Expresiones discursivas en fuentes diversas", este trabajo examina Corinto y su ciudadela Acrocorinto, en sus períodos griego y romano, en alusiones a unos versos o a poemas completos de la Antología Palatina $(A P)$, a fin de sistematizar los rasgos que el imaginario colectivo retuvo y que conservaron los epigramas, en consonancia con las posibles causas movilizadoras que inspiraron a sus creadores. La consulta de Homero, Hesíodo, Heródoto, Píndaro, Pausanias, Estrabón, Higino, Alcifrón, Diógenes Laercio, Cicerón y Elio Arístides, complementa, amplía y corrobora el contenido de los poemas, para una mejor comprensión de la đó $\lambda ı \varsigma$ en la geografía, la historia, la filosofía, el arte, el deporte, la religión, el mito y las costumbres, verificando además los lazos jerárquicos con el resto de Grecia y con Roma.

En la Antigüedad Corinto era bien conocida entre las élites aristocráticas, que la preferían para reuniones sociales. Según Pausanias, era la más idílica de las poleis de la época clásica. Los epítetos

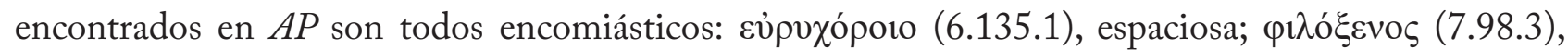

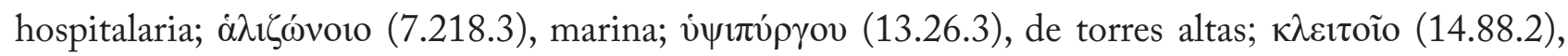
ilustre, digna de ser alabada. Otros calificativos son ỏ $\rho \rho v o ́ \varepsilon v \tau \alpha$ (Hesíodo, fragm. 204.48; Heródoto, Historiae 5.92.línea21; Estrabón, Geographica 8,6,23, línea 53), esto es, situada en altura, elevada; soberbia;

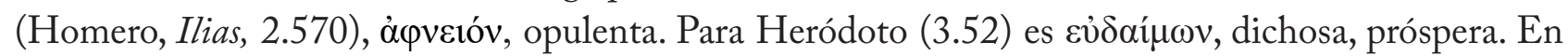
el fragm. 122 Píndaro la considera nuevamente $\alpha \varphi v \varepsilon ı \tilde{\omega}$, rica, acaudalada. Y en su "Olímpica” 13a, v.

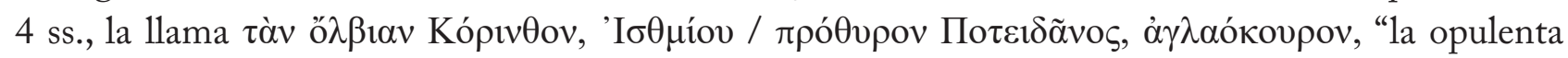
Corinto, de la brillante juventud, que abre el acceso al templo de Neptuno Ístmico”; allí viven las tres hijas de Temis, es decir las virtudes cívicas: Eunomía, Justicia y Paz. En cambio, en 9.284.1 Crinágoras

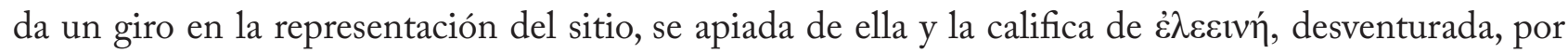
sus impertinentes habitantes cuando deviene colonia romana. Por su parte, Acrocorinto es llamada

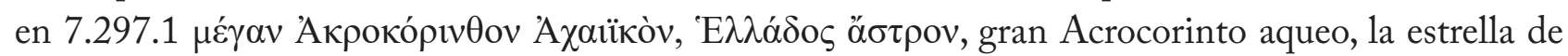
la Hélade.

Una pormenorizada descripción presenta el entusiasta viajero romano Pausanias en el libro II hasta 5.5 (en 6 desplaza sus observaciones a Sición, vecina de Corinto), material que ha servido de guía para los arqueólogos.

A fin de organizar los hallazgos literarios sobre Corinto, este artículo adopta una estructura bipartita: un primer momento, Corinto misma y luego, su vinculación con el resto de Grecia y con Roma.

\section{En el interior de Corinto}

Llamativamente la centralidad corintia en la $A P$ está referida en especial a la situación de la prostitución, que trae aparejada un notorio desnivel económico. 
Situada cerca de un istmo que formaba un puente terrestre entre el Peloponeso y el resto de Grecia, Corinto controlaba dos puertos marítimos y el comercio entre Asia y Roma. Por lo tanto, resultaba un cosmopolita y concurrido centro mercantil y turístico. Y la poblaban marineros, traficantes, comerciantes y paseantes, además de usureros. Se prestaba así para prácticas generalizadas y fuertemente instauradas de libertinaje, de desenfreno, con todo el poder corrosivo que esto conlleva.

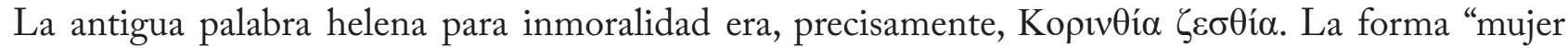

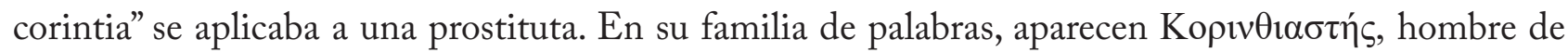

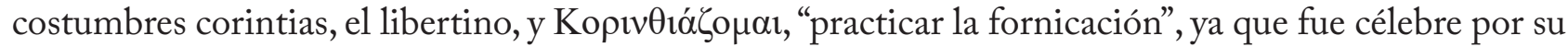
prostitución -sobre todo, la "sagrada, ritual o templaria", un oxímoron desde el punto de vista occidental judeocristiano-. Además, en comedias griegas posteriores, "corintio" se usaba ocasionalmente para designar a un borracho.

Llamada "ciudad de Afrodita", la polis rindió sostenido culto a la diosa, como refleja el comienzo

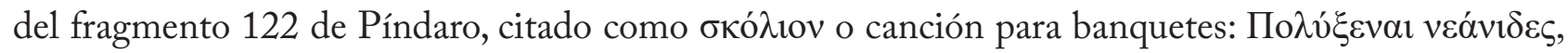

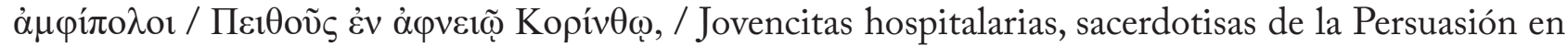
la rica Corinto.

También Geografía 8.6.20 registra la existencia de tales compañías, de las que dependía en gran parte la bonanza del lugar. Tal vez Estrabón exageraba, ya que no era muy diferente de otras ciudades portuarias:

El santuario de Afrodita era tan rico que a título de esclavas sagradas tenía más de mil heteras que tanto hombres como mujeres habían ofrecido a la diosa. También a causa de estas mujeres la ciudad era visitada por mucha gente y se enriquecía; los marinos se gastaban fácilmente todo su dinero, y de ahí viene el dicho: "En Corinto no atraca cualquiera".

Coincidente con el último pensamiento, los latinos habían traducido un proverbio heleno que aludía a los elevados precios de la ciudad y aseguraban: Non cuivis homini contingit adire Corinthum, "No es dado a cualquiera ir a Corinto" (Horacio, Epistulae I.17.36).

Según Estrabón, Corinto se igualaba a los centros orientales, atractivos para los extranjeros por sus costumbres promiscuas. $Y$ era tan fuerte la presencia de las heteras que tenían sus propios asientos en el teatro, como muestra una inscripción.

Años más tarde, Alcifrón inicia su carta de parásitos III. 24, "De Cascobuces a Hipnotrapezo" así: "Y ya no he vuelto a Corinto, porque, en poco tiempo, pude comprobar la sordidez de los ricos de aquel lugar y la miseria de los pobres” y concluye:

La ciudad se encuentra entre dos mares, es agradable de ver y tiene toda clase de lujos; en cambio, en su interior, existen unos habitantes poco agraciados y sin los encantos de Afrodita, a pesar de que ellos dicen que esta diosa, cuando pasó por Citera, rindió un saludo a Acrocorinto. Tal vez Afrodita, defensora de la ciudad, sea la patrona de las mujeres y el Hambre, el de los hombres. 
Corinto se asocia espontáneamente a Lais, ${ }^{1}$ una de las cortesanas corintias más célebres, que vivió en $\mathrm{V}$ a. C., cuyos encantos (Ateneo 588c) descubrió el pintor Apeles. Su tumba erigida en esta $\pi$ $\lambda_{1} \varsigma$ mostraba la escultura de una leona, quizás alusiva a su nombre (Pausanias 2.2.4). ${ }^{2}$ Tan seductora era su presencia que Aristófanes en la párodos de su comedia Pluto la llama la "Circe de Corinto". Es célebre la respuesta de Demóstenes cuando la cortesana le pidió un precio desmedido por sus favores: Paenitere tanti non emo, "No compro tan caro el arrepentimiento" (Aulo Gelio 1.8.6). El epigrama 7.218 es un epitafio y pertenece a Antípatro de Sidón (I a. C.).

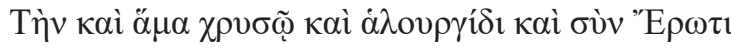

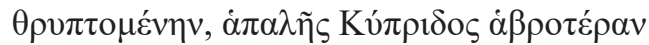

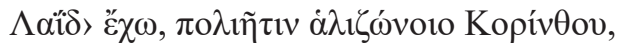

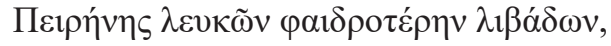

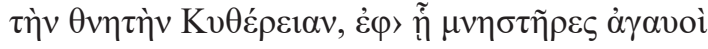

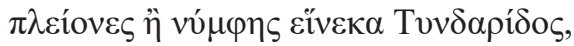

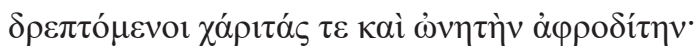

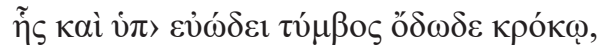

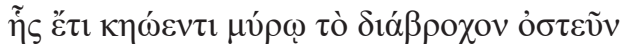

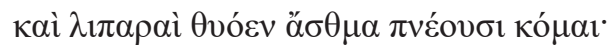

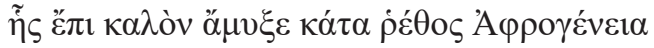

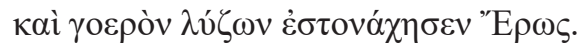

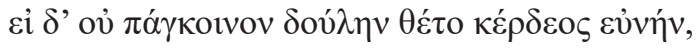

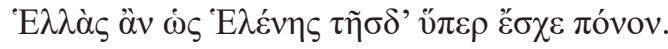

llam simul et auro et purpurea-veste et comite Amore luxuriantem, tenera Cypride delicatiorem

Laïdem cohibeo, civem mari-cinctæ Corinthi, Pirenes albis splendidiorem laticibus, illam mortalem Cytheream, ad quam expetendam proci clari 5 plures exstitere quam virginem ob Tyndaridem, carpentes gratiasque et venalem venerem: cujus et sub odoro-suaviter olet tumulus croco cujus adhuc fraganti unguento humida ossa et nitidæ thuris odorem spirant comæ; super qua pulchram laceravit faciem Spuma-nata, et lacrimosum singultiens ingemuit Amor.

Si vero non communem-omnibus et servum lucri fecisset lectum Græcia, ut ob Helenam, sic hujus causa habuisset bellum.

Lais aquí está, que moró en la marina Corinto y entre oros y púrpuras y Eros a la dulce Cipris venciera en regalo y molicie de vida.

1. El nombre Lais o Laide estaba muy extendido entre las cortesanas.

2. En las monedas corintias aparece con frecuencia la leona con el carnero sobre una columna dórica. 
Límpida como el agua blanca de Pirene, mortal Citerea, a la cual más ilustres amantes

que a la novia Tindáride siguieron, deseando sus gracias poder cosechar y venal Afrodita.

A azafrán aromático huele su tumba; todavía la mirra fragante sus huesos impregna y dulce aliento exhala su brillante cabello.

Por ella Afrogenia arañó sus facciones hermosas

y Eros, sollozando, gimió tristemente.

Común hizo siempre su lecho y esclavo del lucro;

si no, segunda Helena, la Hélade arruinara.

En v. 4 se menciona a Pirene. En realidad, Corinto contaba con dos fuentes así nombradas. Una era un manantial consagrado a las Musas, en la vertiente sur del escarpado Acrocorinto (cfr. Alcifrón, III.15 y Honesto, 9.225); la otra se hallaba cerca del ágora, en la ciudad baja.

Todo el poema recalca su estrecha vinculación con los dioses del amor: "E $\rho \omega \tau \imath$, Kú $\pi \rho 1 \delta o \zeta$,

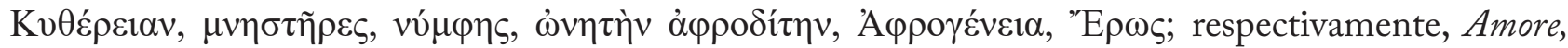
Cypride, Cytheream, proci, virginem, venalem venerem, Spuma-nata, Amor. Además, expresa imágenes, sobre todo olfativas, de suntuoso refinamiento. Lo matiza, sin embargo, una veta irónica: Lais tenía más pretendientes que en su época la hija de Tindáreo y esposa de Menelao aunque, por ser tan fácil ganar sus servicios, no se necesitó repetir la guerra de Troya por su culpa.

En VI d. C., Agacias el Escolástico también se acuerda de Lais ${ }^{3}$ y llama a Corinto con el jónico

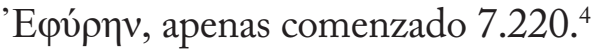

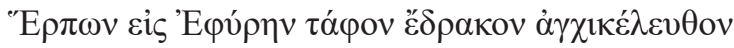

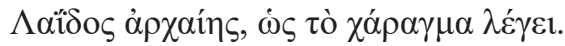

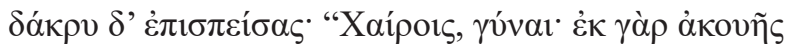

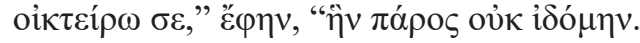

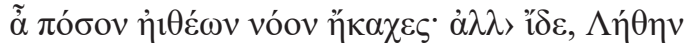

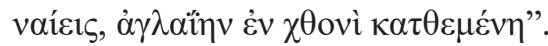

Vadens Ephyram (Corynthus) versus sepulcrum vidi iuxta viam

Laïdis veteris, ut inscriptus titulus indicat.

Ac lacrimam instillans, "Valeas, mulier, nam ex fama

"misereor tui", dixi, "quam olim non vidi"

"Ah quantopere juvenum animum pupugisti!" Sed ecce Lethen

"incolis, pulchritudinem in tellure postquam-deposuisti".

3. Lais está presente en el libro sexto en 1, cuyo autor es Platón; 18, 19, 20 y 71. Y en el 7, en 218 a 220, más el 222.

4. El libro 7 reúne los epigramas sepulcrales o غ̇ंı $\dot{\varepsilon} \pi ı \delta \varepsilon 1 \kappa \tau \imath \kappa \alpha ́$. 
Mientras caminaba hacia Efira, vi la tumba próxima al camino de la antigua Laide, como dice la inscripción, y, derramando lágrimas, dije: “SSalud, mujer! En virtud de tu fama te compadezco, aunque no te había visto antes.

¡Oh! A cuántos jóvenes has trastornado la mente, pero aquí en Leteo

habitas, después de haber depositado tu belleza en la tierra”.

\section{Corinto y su vinculación}

\subsection{Con el resto de Grecia}

En este caso, el ejemplo concerniente a un tratamiento periférico es un personaje histórico: Periandro, uno de los siete sabios, figuró en algunos listados aunque se produjo una escisión en el

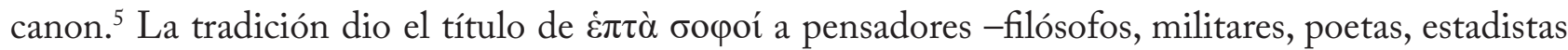
y/o legisladores- datados entre ca. 620 y 550 a. C. Son figuras significativas que desempeñaron un papel destacado durante la época de consolidación de las ciudades helénicas y de sus instituciones en ese período. Recibieron de sus contemporáneos el honor de pertenecer a la lista. Ahora bien, Periandro deja de aparecer como referente según quién liste y según qué punto de vista adopte la fuente examinada: si moral o práctico. Platón y Plutarco, por ejemplo, lo suprimen.

Sin embargo, el epigrama 7.81 de Antípatro de Sidón lo incluye y en el segundo verso alude a

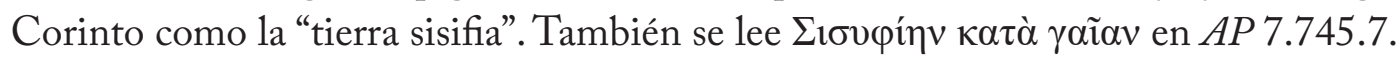

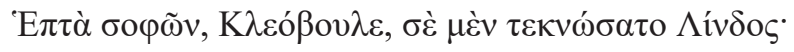

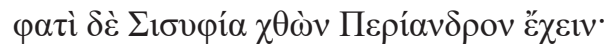

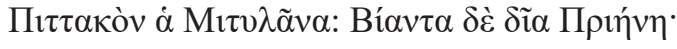

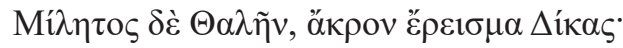

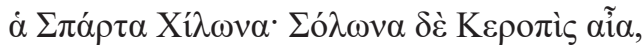

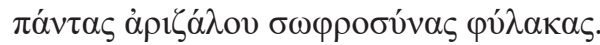

Septem e-sapientibus, Cleobule, te quidem genuit Lindus, ait autem Sisyphea tellus Periandrum habere ;

Pittacum Mitylene; Biantem vero dia Priene;

Miletusque Thaletem, summum fulcimentum Justitiæ

Sparta Chilonem; Solonemque Cecropia terra,

omnes valde-æmulandæ sapientiæ custodes.

De los siete sabios, Cleóbulo, a ti te engendró Lindos;

dicen que la tierra sisifia lo tuvo a Periandro,

5. La forma en que Simónides refuta las máximas de Pítaco (fr. 542) y de Cleóbulo (fr. 581) sugiere que el кavóv se estaba formando, o había quedado establecido, a principios del $\mathrm{V}$ a. C., aunque el primer testimonio explícito del septeto aparece en Platón (Protágoras o Los sofistas 343b y Cármides 165a). 
a Pítaco, Mitiline; a Bias, la divina Priene;

Mileto a Tales, excelso baluarte de la Justicia;

Esparta, a Quilón y a Solón, la cecrópide tierra,

todos custodios de admirable prudencia.

De igual tenor es la fábula 221 de Higino:

Pítaco de Mitilene, Periandro de Corinto, Tales de Mileto, Solón de Atenas, Quilón de Lacedemonia, Cleobulo de Lindo, Biante de Priene. Sus máximas son las siguientes: 2. "Lo mejor es la mesura", dice Cleobulo, habitante de Lindo; Periandro de Éfira, tú enseñas que: "Todo debe ser meditado"; "Conoce el tiempo", dice Pítaco, natural de Mitilene; "La mayoría son malvados", afirma Biante de Priene. Tales, el milesio, amenaza al fiador por los daños. "Conócete a ti mismo", dice Quilón, natural de Lacedemonia. Solón, el cecropio, aconsejó "nada en exceso".

El hieroglifo o emblema de Periandro era una mata de poleo con esta palabra: "Modérate", porque esta planta tenía fama de sosegar la cólera. Su mandato (VII-VI a.C.) se caracterizó por una duradera prosperidad y estabilidad. Como los tiranos eran mecenas de las artes, a su corte asistió el poeta Arión (cfr. la leyenda en Heródoto I.24). Y, pese a que reglamentó y humanizó el régimen de trabajo de los esclavos, y mejoró y pavimentó el $\delta$ ió $\lambda \kappa \varsigma_{\varsigma},{ }^{6}$ canal o pasaje a través del itsmo de Corinto con fines económicos, comerciales y militares que unía los mares Jónico y Egeo (Estrabón 7.2.1), las generaciones posteriores consideraron inapropiado incluir a un tirano y lo quitaron del acreditado grupo.

Un dato más ilustra la hospitalidad corintia: el filósofo cínico Diógenes de Sínope también pasó la última etapa de su vida allí, donde divulgó su doctrina, murió y fue sepultado. Y célebre es su

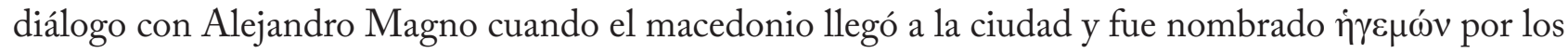
aliados.

Corinto mantuvo su centralidad en aspectos asociados con el arte, por ejemplo en expresiones poéticas, cerámicas, pictóricas y arquitectónicas. Entre sus referentes, es corintio el poeta épico del VIII a. C., Eumelo, un Baquiada, cuya dinastía inaugura el período realmente histórico. Se le atribuye, entre sus obras, Corintbiaca, una epopeya histórica mediante la cual confirió a su patria un pasado legendario que hiciera olvidar su sometimiento a Argos durante la época micénica. He aquí la literatura al servicio de la política.

Tres siglos más tarde, todavía eran muy ponderados los vasos del alfarero Tericles (V a. C.). De hecho, sus copas recibieron en su memoria el calificativo de "tericleas". Fue contemporáneo de Aristófanes y la Comedia Nueva lo menciona varias veces. Eran también coterráneos el pintor Ifión, conocido gracias a $A P$ 9.757, ensalzado por Simónides de Ceos, y el epigramista Honesto, aunque a este se lo considera asimismo bizantino. En Corinto surgió además uno de los más bellos y consistentes

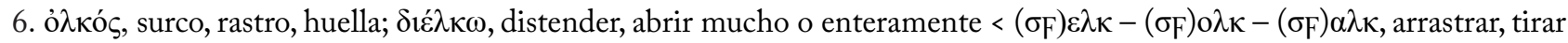
(raíz n 125 en Eterovic). En Corinto el pasadizo tenía unos $7 \mathrm{~km}$ de longitud, con dos surcos separados por metro y medio a modo de rieles. Se pagaba peaje. 
órdenes arquitectónicos y su bronce era de excelente calidad. Allí estaban los mejores hornos de todo el Mediterráneo. Y sus artesanos exportaban por doquier productos muy cotizados.

Un rasgo particular, asentado en la $A P$, fue su aceptación a presuntos perseguidos políticos. En 7.98 Diógenes Laercio recuerda el exilio de Jenofonte y su familia. Según los registros históricos, se trató de una estancia temporal que comenzó en 395/4 o al inicio de 394/3. La elección para su destierro es indicativa de las condiciones beneficiosas que ofrecía al extranjero, en este caso por afinidades políticas. La partícula oracional inicial Eỉ אà̀ oé indica que no ha sido el único en buscar allí su acogida.

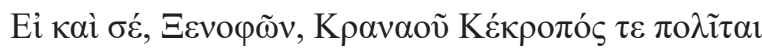

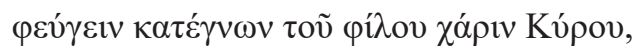

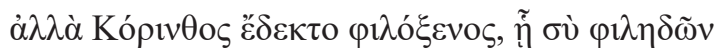

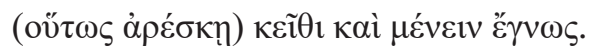

Etsi te, Xenophon, Cranai Cecropisque cives exulare decreverunt amicum ob Cyrum,

at Corinthus excepit benigno-hospitio, in-qua tu lubenter degens sic es-contentus ibique manere decrevisti.

Aunque a ti, Jenofonte, los ciudadanos de Cécrope y de Crónao te condenaron a exiliarte, por tu amigo Ciro,

pero Corinto hospitalaria te recibió, en la cual tú te complaciste y decidiste permanecer allí.

La paronomasia - esto es, la presencia de palabras con una misma raíz- apunta en este caso a subrayar lazos de amistad: $\varphi$ í $\lambda$ ov en el verso segundo, $\varphi \imath \lambda o ́ \xi \varepsilon v o \varsigma$ (...) $\varphi \imath \lambda \eta \delta \tilde{\omega} \nu$ en el siguiente. La antinomia es evidente: Atenas lo expulsa; Corinto lo alberga. Ese amable recibimiento está reforzado por Dion Crisóstomo (o Dion de Prusa), en I d. C. En su Discurso XXXVII (a los corintios) les agradece la acogida en su segunda visita: "no me honraron como a uno de esos muchos que arriban cada año al puerto de Céncreas -comerciante, peregrino, mensajero o pasajero-, sino como a una persona querida que por fin aparece después de largo tiempo de ausencia”.

Otro ángulo de estudio respecto de la sociedad corintia son los juegos ístmicos. Su historia refleja la importancia central de esta práctica en el terreno político-religioso. Cada dos años, en primavera, se celebraban las competencias panhelénicas en el istmo de Corinto en honor de Posidón. ${ }^{7}$ En la saga corintia, la mejor atestiguada, Sísifo los había instituido en el XIV a. C. en honor de su pariente Melicertes. Los corintios ejercían como jueces y los certámenes eran los mismos que en Olimpia. El poema 6.246 registra una victoria en tales competiciones.

En sus inicios, 581 a.C., la ciudad era la encargada de organizarlos. Argos la dominó a principios del IV a.C. y controló entonces la preparación de los torneos. En 390 a. C. Agesilao los restituyó a los

7. Han quedado siete epinicios ístmicos completos de Píndaro. 
lugareños pero, cuando el espartano se marchó, los argivos recobraron el mando hasta que lo perdieron definitivamente en 386 a.C. En IV.2 "De Glícera a Báquide” de Alcifrón, la cortesana -y amante del viajero- escribe desde Atenas e inicia su carta a la hetera corintia comentando: "Mi Menandro ha decidido ir a Corinto para asistir a los Juegos Ístmicos", evidencia de que eran muy frecuentados.

Otro momento en los epigramas alude al combate naval de Salamina (480 a. C.) entre las ciudades-estado griegas y la flota del imperio persa. En el V a. C., Simónides de Ceos registra en 7.250 su excelente desempeño. Los dísticos estaban grabados en la tumba de los caídos corintios, cuya piedra ha sido encontrada.

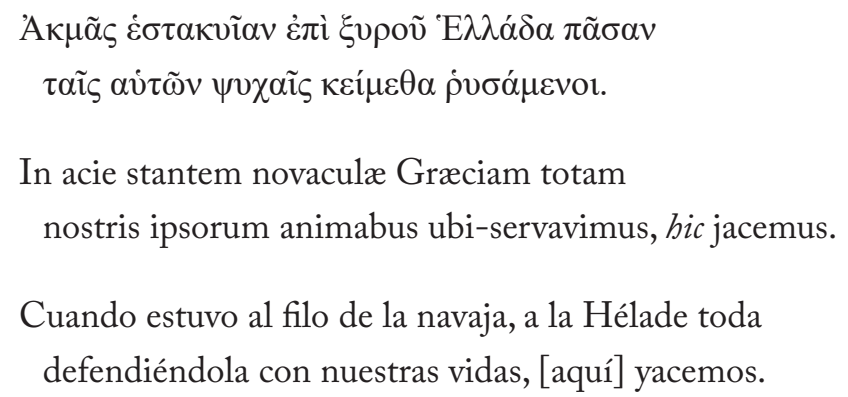

\subsection{Con Roma}

"Corinto fue sin duda una de las ciudades más importantes y representativas de Grecia bajo la égida romana”, afirma Fornis (2007, p. 205).

En 9.284, Crinágoras de Mitilene se queja acongojadamente a finales del I a.C., sobre la baja

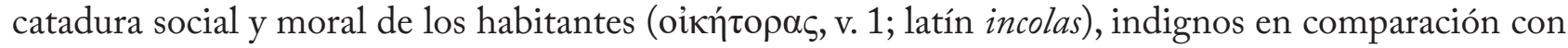
sus antiguos pobladores. Las fuentes explican que los colonos eran principalmente libertos carentes

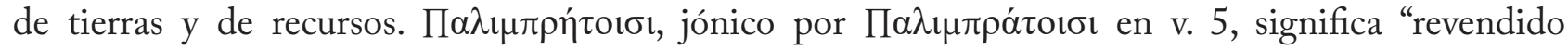
constantemente (hablando de un esclavo)"; por extensión, “mala persona, miserable”. Paton (II, 1958, p. 153-154) aclara: "This refers to the re-colonization of Corinth by Julius Caesar, a measure usually praised. The colonists were freemen; Crinagoras speaks of them as if there were slaves".

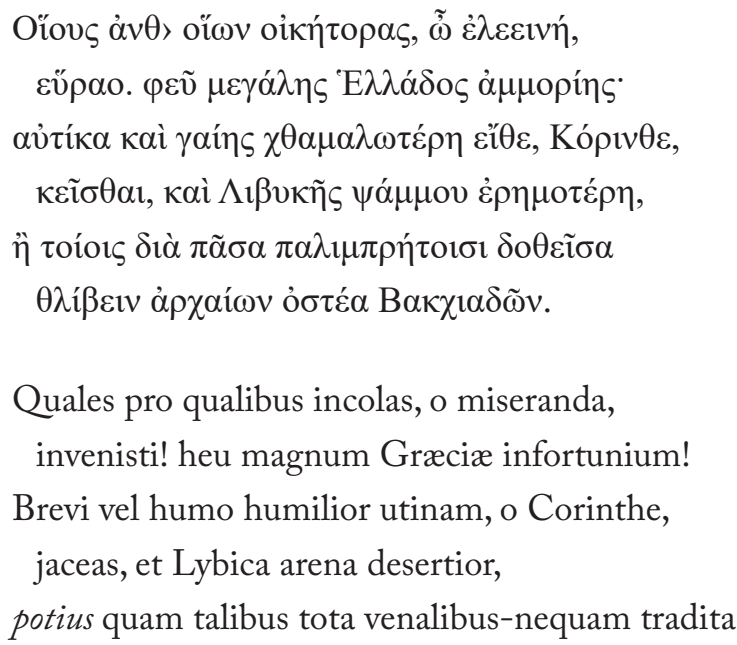


premas antiquorum ossa Bacchiadarum.

¡Vaya colonos y en lugar de cuáles, desdichada,

has encontrado! ¡Ay, desventura de la gran Grecia!

Incluso preferiría verte más postrada que la tierra, Corinto,

y yacer más árida que las arenas de Libia,

antes que subyugada por completo a semejantes esclavos

que oprimen los huesos de los antiguos Baquíadas.

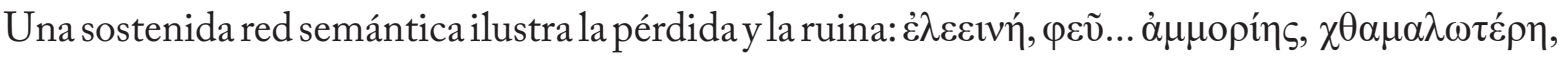
$\dot{\varepsilon} \rho \eta \mu \tau \varepsilon \dot{\rho} \rho \eta, \theta \lambda i ́ \beta \varepsilon v$; en latín, respectivamente, miseranda, heu... infortunium, humilior, desertior, premas.

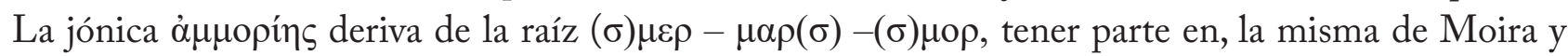
de $\mu \varepsilon i ́ p o \mu \alpha$, obtener por suerte su parte. El poema remata, nostálgico, con la alusión a la familia de la nobleza doria de Corinto, descendientes de Baquis, hijo de Prumnis. Este clan, formado por unas 200 familias, gobernó entre 750 y 620 a.C. aproximadamente (cfr. Heródoto 5.92).

En 45 a.C. Julio César reedificó la ciudad con el nombre de Colonia Laus Julia Corinthensis. Fue nombrada capital de la provincia romana de Acaya, se reedificaron sus templos, comercios y mercados, erigieron edificios públicos y desarrollaron un nuevo sistema de acueductos. Entre 7 y 3 a.C. su gobernador Lucio Castricio Régulo recuperó la organización de los juegos, que seguían celebrándose a fines de la época imperial. Y es revelador que el cónsul Tito Quinto Flaminino hubiera elegido estos

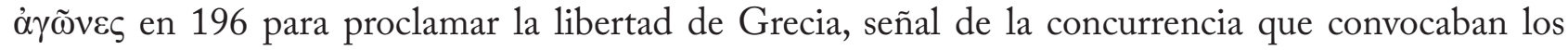
certámenes. En 146 a. C., después de la última guerra contra la Liga Aquea y de la definitiva sumisión de la Hélade, Lucio Mumio devastó la ciudad, según asegura Dion Casio (Historia romana XXI, 31.8), aunque la arqueología ha demostrado que la destrucción, en realidad, no fue absoluta. Es verdad que, si bien se había restaurado el recinto donde se arbitraban las competencias deportivas, estas se delegaron a Sición.

En 7.297 Polístrato de Letópolis, Egipto (II a. C.) poetiza el estrago y la venganza de los itálicos:

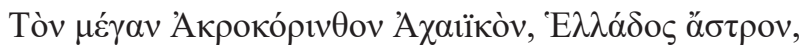

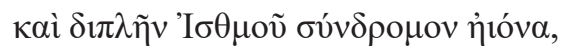

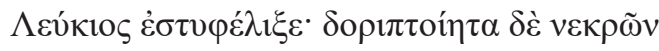

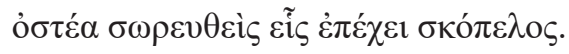

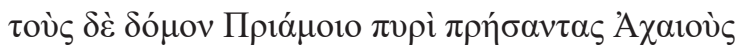

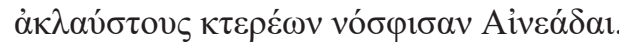

Magnum Acrocorinthum Achæorum, Græciæ astrum, et duplex Isthmi concurrens littus

Lucius evertit: sed hasta sparsa mortuorum (congeries), ossa accumulatus unus continet scopulus (saxorum).

Qui autem domum Priami igne combusserunt Achæos non-defletos sepulcro fraudarunt Æneadæ (Romani). 
El gran Acrocorinto aqueo, la estrella de la Hélade, y la doble ribera que corre a la par del istmo

Leucio arrasó, y los huesos heridos de lanzazos amontonados un solo peñasco recubre

y a la casa de Príamo quemaron los aqueos

no llorados, los privaron de honras fúnebres los Enéadas.

Con su ruina los itálicos, descendientes de Eneas (el general romano es llamado aquí Leucio), se han resarcido de aquellos helenos que habían incendiado Troya y masacrado el linaje del rey. La

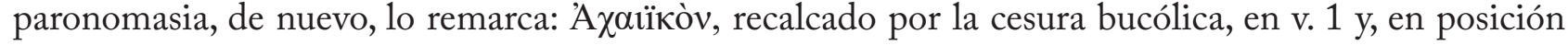
privilegiada final, A $\chi \alpha$ ıov̀ s en 5, elocuentemente enfrentado a Aiveć $\delta \alpha 1$, que queda resonando, en la

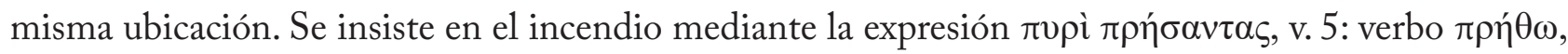
quemar, más $\pi v \rho i ́$, con fuego. En el tercer verso la voz épica $\dot{\varepsilon} \sigma \tau \varphi \varphi \varepsilon ́ \lambda 1 \xi \varepsilon$ (evertit latino), remarcada por

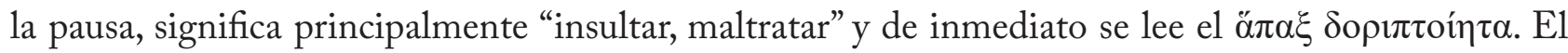

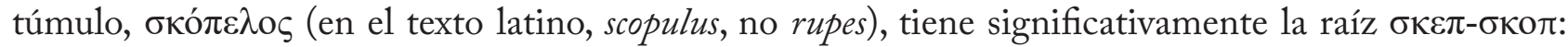
“observar con detenimiento, como advertencia y reivindicación” y cubre a las víctimas una verdadera montaña. El adjetivo $\mu \varepsilon ́ \gamma \alpha v$, al principio del poema, significa grande (magnum latino), en varios sentidos como altus, longus, latus, amplus...; de hecho, el Acrocorinto era una inexpugnable roca de 575 $\mathrm{m}$ de altura. Pausanias en VII.16.8 relata que la mayor parte de los varones fueron muertos y mujeres y niños, vendidos como esclavos. La victoria romana se acrecienta, con dimensiones épicas.

También Antípatro de Sidón escribe una emotiva e inspirada elegía (AP 9.151) tras la toma de Corinto por Lucio. Bajo el tópico del $\pi$ oṽ cióí, del ubi sunt, 9.151 confirma la nostalgia ante el brillo y

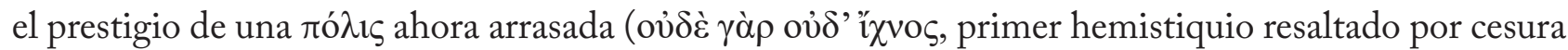
pentemímera). ${ }^{8}$ Cantan significativamente las Nereidas, muy veneradas en la ciudad. ${ }^{9}$ En el primer verso, la diéresis bucólica concede aun mayor valor rítmico a los vocativos con el intencional gentilicio de origen que remite a su mentor Doro, fundador epónimo:

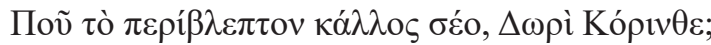

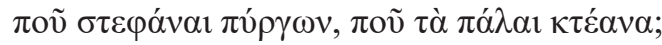

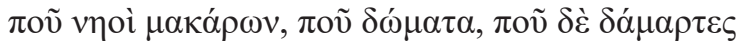

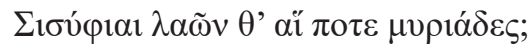

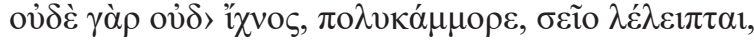

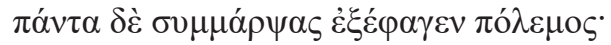

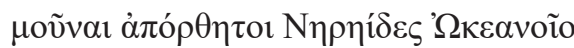

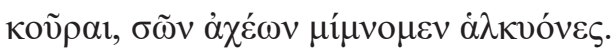

Ubinam illa conspicua pulchritudo tua, Dorica Corinthe, ubi coronæ turrium, ubi antiquæ divitiæ.

ubi templa immortalium, ubi domus, ubi vero matronæ

8. Es un tópico característico de los lamentos sobre ciudades destruidas.

9. Las ninfas tenían poderes oraculares y proféticos, notado por Pausanias, por ejemplo, en 8.37.11 y en 10.5.5. 


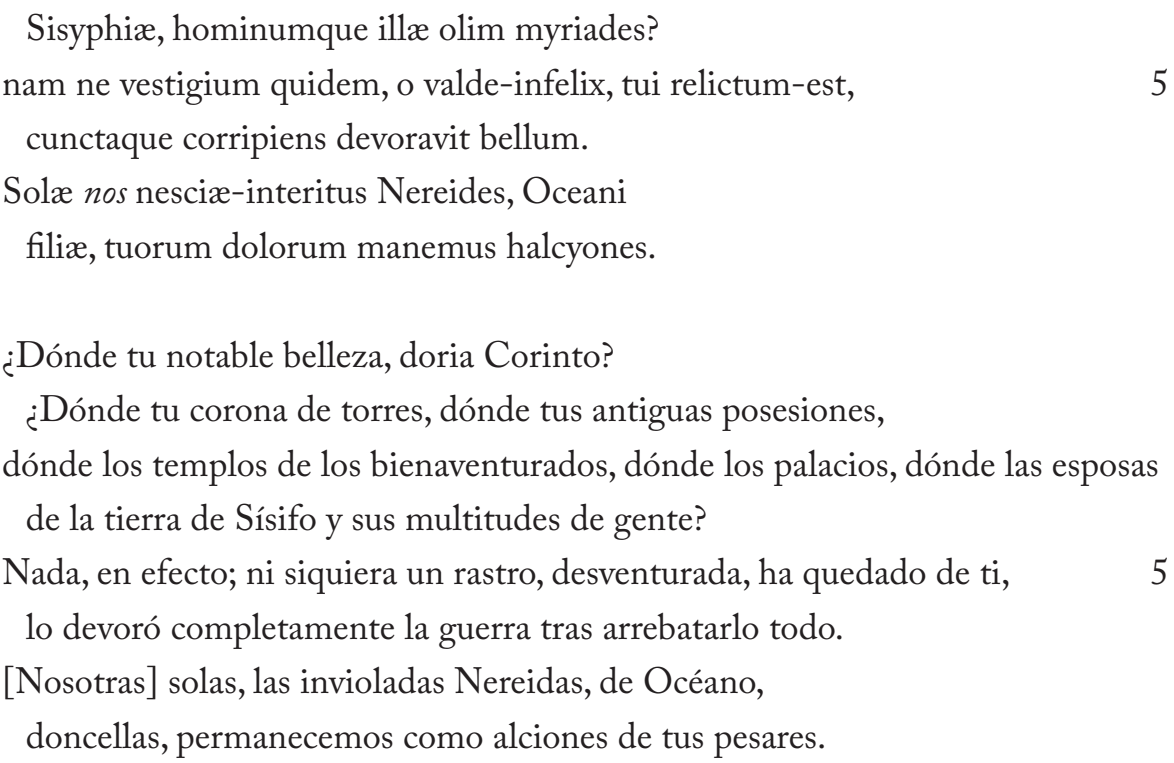

El dominio romano provocó la ruptura cultural y biológica con el núcleo anterior. Se añora y se valora su pasado -que el arte poética recupera-. Se siente, se sufre, el abandono y la desaparición de sus costumbres y posesiones, bienes entrañables de uso colectivo:

existen algunos indicios de que la élite corintia, a partir del siglo II d. C., trató activamente de asociarse al pasado helénico (...). La destrucción de Corinto es, por lo tanto, un tópico recurrente, así como también lo es el hecho de que la nueva pólis no tenga nada que ver con la anterior. (Moreno Leoni, 2014, p. 68-69)

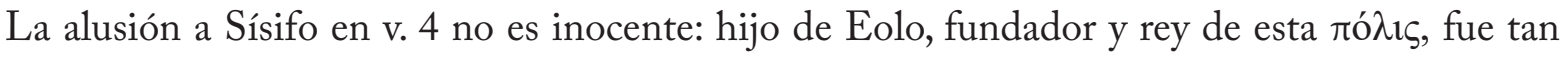
temible por sus crueldades y robos que Teseo lo mató y en el Hades se lo condenó a subir una enorme piedra la cual, al llegar a lo alto, volvía a caer. ¿Es entonces consecuencia de sus actos que la otrora poderosa Corinto sucumbiera? En este marco mitológico, las Nereidas, ninfas del mar calmo, las que presiden tanto la fertilidad y los nacimientos como la muerte y la disolución, son las encargadas de la evocación fuera del tiempo histórico. No es casual su aposición, reforzando su entronque: doncellas

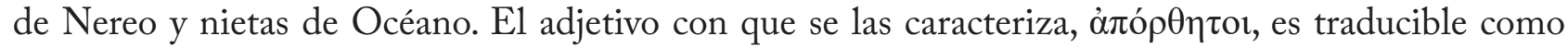
"no saqueado", "inexpugnable", en directa referencia al opuesto y brutal ocaso de la ciudad. Por su parte, la comparación con el alción pone la cuota de espiritualidad y de rapidez intrínseca propias del simbolismo del ave, además de su dosis de luto, junto con un eco de la historia mítica sobre Alcione, ${ }^{10}$ también hija del rey de los vientos Eolo, transformada en alción por Zeus y Hera enojados (cfr. Apollod. 1.7.4, Ov. Met.11.410-750).

En este poemita Corinto es así mismo símbolo de los ciclos propios de cada gran ciudad, según el lema "a gran altura, gran caída", colapso ocasionado por el accionar humano errado.

10. Alcione o Alcíone, según Fernández Galiano (1969). Igualmente, por decisión de Zeus la madre de Aedón, Harmótoe, es metamorfoseada en esta ave marina, también llamada martín pescador. 


\section{A modo de cierre}

Según la mitología, su denominación inicial es Éfira. Así la llama Homero (Ilíada 6.152), la refuerza con la explicación "donde Sísifo el Eólida vivía” y la ubica entre los territorios bajo el mando de Agamenón en la guerra de Troya. De Éfira es originario, por ejemplo, Belerofonte, a quien se lo honraba allí como héroe.

Como Corinto gozó de largas etapas de prodigalidad (de hecho, fue una de las primeras ciudades helenas en utilizar la moneda), Pausanias (II.1.8) comenta que allí recibía culto Bonanza, diosa ubérrima porque facilita el tráfico marítimo y, en definitiva, la abundancia. En el v. 7 del epigrama

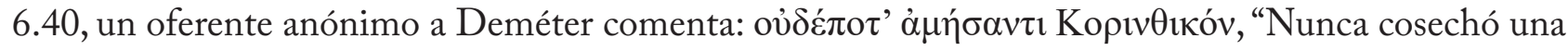
rica cosecha corintia”, porque la franja entre Corinto y Sición era famosa por su riqueza.

Tan visitada como admirada por su opulencia y desenfreno, llegaría sin embargo el día en que se derrumbase. No obstante, el destino haría que se convirtiera en el centro del primer cristianismo en Grecia en tiempos de Pablo. Para el siglo I d. C., su centro comercial era mayor que cualquier otro en Roma y, cuando llegó Pablo de Tarso, era una de las ciudades más notables en la región. ${ }^{11}$ El libro de Hechos explica que, luego de predicar en Atenas, el apóstol viajó 50 millas [80.5 km] hasta Corinto. Y no fue casual su elección del lugar, aunque sus decisiones misioneras no han sido explicitadas.

Si revisamos la historia a través de los epigramas encontrados en $A P$, y a pesar de la tensa vinculación con Atenas y luego de los desentendimientos con Roma, Corinto gozó más de una situación nuclear que periférica. En el II d. C., el orador y sofista griego Elio Arístides (Discursos XLVI, 22-29) la elogia con exaltada admiración en un extenso pasaje, no por remoto menos poderoso, del cual se extrae este elocuente extracto:

Si de la misma manera que se puede conceder el título de «proxeno» a los hombres también se lo pudieran otorgar las ciudades entre sí, esta ciudad habría merecido este título y honor en todas partes. Pues recibe en su seno a todas las ciudades y de nuevo las envía desde ella; es el refugio común de todos, como si se tratara de una ruta y encrucijada por donde todos los hombres deben pasar, no importa a qué lugar uno quiera viajar. Es la ciudad común de todos los griegos, como si, sencillamente, fuera su metrópolis y su madre.

\section{Referencias bibliográficas}

Conejo, A. M. E. (1987). Los siete sabios de Grecia. Enfoque crítico. Filología y Lingüistica, XIII (2), 95-101.

Cortés Copete, J. M. (trad.) (1999). Elio Arístides. Discursos V. Madrid, Gredos.

Difabio, E. H. (2015). Un mapa de la nostalgia: ciudades otrora resplandecientes en el libro 9 de la Antología Palatina. Anales de Filología Clásica, 28, 5-18.

11. Pablo visitó Corinto en más de una ocasión: cuando escribe 2 Cor 10-13 afirma que está por ir a la ciudad por "tercera vez" (cf. 2 Cor 12,14; 13,1). 
Dübner, F. (ed.) (1872). Epigrammatum Anthologia Palatina cum Planudeis ET appendice nova (Volumen Primum). Parisiis, Firmin-Didot et Sociis. https://bit.ly/3g71WYr.

Esclasans, A. (trad.) (1968). Pindaro. Himnos triunfales. Barcelona, Obras Maestras.

Fornis Vaquero, C. (2007). La construcción de la identidad romana en Corinto. Habis, 38, 205-224.

García Gual, C. (2007). Los siete sabios (y tres más). Madrid, Alianza.

Herrero Ingelmo, M. C. (trad.) (1994). Pausanias. Descripción de Grecia. Libros I y II (T. I). Madrid, Gredos. https://bit.ly/3w89E7v.

Liñares, L. (trad.) (2005). Hesiodo. Teogonia. Trabajos y días. Buenos Aires, Losada.

Magnelli, E. (2007). Meter and Diction: From Refinement to Mannerism. En Bing, P. y Bruss, J. S. (eds.), Brill's companion to Hellenistic epigram (pp. 165-183). Leiden, Brill.

Martos Montiel, J. F. (2002). Sexo y ritual: La prostitución sagrada en la Antigua Grecia. En MartínezPinna, J. (coord.), Mito y ritual en el antiguo Occidente mediterráneo. https://bit.ly/3g7f5hD.

Morcillo Espósito, G. (ed.) (2008). Cayo Julio Higino. Fábulas. Astronomía. Madrid, Akal.

Moreno Leoni, Á. (2018). Entre el helenismo y el imperio romano. La visita de Pausanias a Corinto. Byzantion nea hellás, 37. https://bit.ly/3ivlsN6.

Negrete, J. (2016). La gran aventura de los griegos. Buenos Aires, El Ateneo; Madrid, La Esfera de los Libros.

Paton, W. R. (ed.) (1956-1958). The Greek Anthology (vol. II y III). London/Cambridge, Harvard University Press.

Pippin Burnett, A. (2011). Servants of Peitho: Pindar fr.122 S. Greek, Roman, and Byzantine Studies, 51, 49-60. https://bit.ly/3v9ISu6.

Pontani, F. M. (ed.) (1979). Antologia Palatina (Vol. Secondo, Libri VII-VIII). Turin, Giulio Einaudi Editore.

Ruiz García, E. (trad.) (2000). Alcifrón. Cartas. Madrid, Gredos.

Sánchez Ortiz de Landaluce, M. (2009). Elementos míticos en el epigrama inscripcional. En Martínez Fernández, Á., Estudios de Epigrafía Griega. Serie investigación 1, La Laguna, Servicio de Publicaciones, Universidad de la Laguna. https://bit.ly/3pBQg0g.

Serna, E. de la (2019). Primera carta del apóstol San Pablo a los cristianos de Corinto. Comentario. Navarra, Editorial Verbo Divino. https://bit.ly/3pBR0T6.

Vicuña, J.y Sanz de Almarza, L. (1998). Diccionario de los nombres propios griegos debidamente acentuados en español. Madrid, Ediciones Clásicas. 
*Elbia Haydeé Difabio es Profesora, Licenciada y Doctora en Letras (orientación Filología Clásica). Categoría 1 en SIIP. Dirige y codirige becarios y tesistas de grado y de posgrado en UNCuyo, UCC y UNSJ. Colabora en Banco de Consultores de CONICET, Registro de Expertos de CONEAU, Banco de Evaluadores de la Secretaría de Investigación y Desarrollo de UBA, UNTREF, UNQ, UM, UNSJ, UNLPam, UNT y UCA. Autora y coautora de libros, evaluadora (en el país, México y Chile) y autora de artículos en revistas especializadas y actas en Argentina y en el extranjero (España, Chile, Venezuela, Bolivia, Brasil). Miembro de Comités Científicos Internacionales en Argentina, México, Chile y España.

RECIBIDO: 03/05/2021

ACEPTADO: 03/06/2021 